\title{
Finding the reasons of decrease in the rate of population growth in Iran using causal layered analysis (CLA) method
}

\author{
Mohammad Hossein Mehrolhassani ${ }^{1}$, Saeid Mirzaei ${ }^{2}$, Samira Sadat Poorhoseini ${ }^{3}$, Nadia Oroomiei*3
}

Received: 5 Mar 2018

Published: 4 Sep 2019

\begin{abstract}
Background: According to census 2011, general fertility rate in Iran was 1.6 children. The United Nations published a low population growth scenario for Iran in 2010, and if Iran continues to experience population replacement and does not have a plan to balance it, it will experience a population of 31 million, with a high percentage of elderly people in the next 80 years. This study was conducted to identify the causes of a decrease in population growth rate.

Methods: This was a secondary study conducted by reviewing the scientific texts, papers, and upstream documents. The upstream documents contain all national documents related to population decline in Iran. Causal layered analysis (CLA) was used for data analysis.

Results: The 9 most important identified causes for a decrease in population were litany (child mortality, maternal mortality, diseases burden, fertility rate, marriage squeeze, abortion, marriage age, high-risk behaviors, and badly supervised and neglected children. Also, 5 causes in structural layer were urbanization, education rate, economic participation rate and unemployment rate, new structures, a change in family structure, and intergenerational gap. Moreover, three causes in discourse layer included welfare, materialism, individualism, and 2 causes in metaphor layer were changing the perception of life and family formation, and women as workforce.

Conclusion: It seems that the decrease in population growth in Iranian society is less the result of social planning and population control and more the result of the value and structural changes that have been occurred due to modernization in the society. It is recommended that policymakers primarily address the discourse and metaphor layers to solve the problems.
\end{abstract}

Keywords: Causal layered analysis (CLA), Population decreasing, Iran

Conflicts of Interest: None declared

Funding: None

\section{*This work has been published under CC BY-NC-SA 1.0 license.}

Copyright $\odot$ Iran University of Medical Sciences

Cite this article as: Mehrolhassani MH, Mirzaei S, Poorhoseini SS, Oroomiei N. Finding the reasons of decrease in the rate of population growth in Iran using causal layered analysis (CLA) method. Med J Islam Repub Iran. 2019 (4 Sep);33:92. https://doi.org/10.47176/mjiri.33.92

\section{Introduction}

The population control policies and quality of population have long since been considered because population is the source of power and is the pillar of the development and improvement of any society (1). Negative consequences of population decrease are lack of economic growth, aging, generation discontinuity, disruption of social communication among children of low-population families, and mental and psychological problems due to

Corresponding author: Nadia Oroomiei, n.orumieh@kmu.ac.ir

1. Social Determinants of Health Research Center, Institute for Futures Studies in Health, Kerman University of Medical Sciences, Kerman, Iran

2. Department of Health Management, Policy and Economics, School of Public Health, Bam University of Medical Sciences, Bam, Iran

3. Health Services Management Research Center, Institute for Futures Studies in Health, Kerman University of Medical Sciences, Kerman, Iran the lack of familial ties (2).

Many developing countries face a declining population, a trend different from the declining population in developed countries. The population decline in developed countries has occurred after experiencing economic growth and improving the living conditions. The population decline in developing countries has occurred prior to the improvement of living conditions, and it is faster than that in de-

$\uparrow$ What is "already known" in this topic:

Iran has experienced an unprecedented decline in fertility rates over the past 30 years. Among the negative consequences of population decreasing, the lack of economic growth and the aging of the society can be mentioned.

\section{$\rightarrow$ What this article adds:}

This article identified the causes of population decline in Iran by documentary review and CLA method to be used in population policy and planning. 
veloped countries. Iran, as a developing country, is not an exception (3).

Throughout history, Iran has experienced an unprecedented decline in the population. In 1970, there was an average of 6.5 children per Iranian woman, which dropped to 1.6 child per woman in 2011 , which is below the fertility replacement rate $(4,5)$.

The fertility rate in Iran has had an ascending descending trend over the past few decades. In the early 1970s, a moderate decline occurred in fertility from 6.5 in 1970 to about 6 in 1976. Following a rebound between 1976 and 1980 (increase of up to 7 in 1980), which coincided with the Islamic Revolution in 1979, and Iran-Iraq war (1980), the decline has resumed since the mid-80s. The family planning plan was also accelerated in 1979 (decrease from 6.8 in 1984 to 6.3 in 1986, and to about 5.5 in 1988) (4, 6). The extreme decline rate from 5.5 in 1988 to about 2.8 in 1996 reached 2.2 in 2000 (7).

These changes can be clearly linked to the population policies at each stage. For example, an antinatalist policy, at the end of the imperial regime, was the family planning program that was not accepted by the public due to the lack of support from religious leaders, which led to a slight decline in fertility at that time. Subsequently, by criticizing the family planning program and encouraging early marriage in the post-Islamic revolution of Iran and at the end of Iran-Iraq war, it returned to its antinatalist policy (8), which is strongly opposed by the Supreme Leader, Ayatollah Ali Khamenei. He has been demanding the suspension of the antinatalist policy and finding a pronatalist policy due to issues related to the aging population.

Although Iran has adopted pronaturalist policies, statistics shows that it has not yet been able to reach the population replacement rate (9). This can be due to the lack of determination in the reasons for the problem of population decline in the root and in the underlying layers of the problem (10). Although many studies have been conducted on the factors influencing the increase and decrease in Iranian population, few studies have been conducted on the causes of population decline by determining the root causes. Given the importance of population and its favorable growth in Iran, the present study aimed to identify the various causes of decrease in population growth rate in Iran using CLA technique.

Soheil Enayatolah proposed a method for a deep investigation in the layers producing a problem, called causal layered analysis (CLA) (11), which has been employed by a few researchers (12-14). In this method, the reason for the appearance of a phenomenon is examined in 4 layers, each more rooted and general than the previous one (15).

\section{Methods}

This was a secondary study conducted by reviewing scientific texts and papers and upstream documents which contain all national documents related to population decline in Iran, developed and published by government organizations. Documents were provided by private organizations, but the newspapers were excluded from the study. The research team identified key upstream documents through examining the websites of the ministries and referring to several government organizations including Iranian Statistics Organization, Ministry of Health and Medical Education, State Welfare Organization of Iran, and National Organization for Civil Registration. The research team selected relevant documents based on 4 key factors: authenticity (being original and genuine), credibility (accuracy), representativeness (being representative of the totality of the documents in their class), and meaning (what they say) (16).

The documents included Iranian Demographic Policy (considerations and perspectives) (17), Youth Health Document (18), issued missives by Supreme Leader Ayatollah Khamenei (19), Iran's Multiple Indicator Demographic and Health Survey (20), Health Indicators in the Islamic Republic of Iran (21), analysis of the general population policies of the Supreme Leader Ayatollah Khamenei (22), Population and Housing Census (9), time series of the population (23), time series for marriage and divorce (24), Abortion Report (25), the first to sixth program of economic, social and cultural development of the Islamic Republic of Iran (26-31), child mortality in Iranian indices and trends from 1956 to 2021 (32), IslamicIranian Model of Progress (33), indices of employment and unemployment over the period of 1997-2012 (34), Health Indicators (35), and Adolescent and Youth Reproductive Health Documents of Islamic Republic of Iran (36).

The documents were repeatedly studied by 3 members of the research team. Some parts of the texts were cited for reasons and consequences of population decline were selected as units of analysis. Disputes were reviewed and agreed upon through a meeting with the research team. CLA framework was employed for data analysis.

Based on this method, in the first layer, called litany, the most superficial data are analyzed, representing the official and accepted view of reality. The second layer is social causes, indicating the organized views. The third layer concerns the analysis of worldview and discourse. At this layer, argumentation assumptions, which are unconscious, and based on the context of ideologies and world view, are analyzed. Finally, the fourth layer indicated myths and metaphors, representing the unconscious motivational dimensions of the subject embodied in the form of myth and metaphor (10).

In this study, the cause of population decrease was investigated according to CLA technique. In the first place, the most tangible causes appeared in 2 layers of litany and social causes. However, a deeper analysis of the subject led to the emergence of the 2 following layers (the discourse layer and the metaphor and myth layer), each with its cause, and more general and rooted in the problem than the previous layer.

\section{Results}

The findings were identified through reviewing these documents. The identified causes were classified into 4 layers: litany, social causes, discourse, and myth/metaphor (Fig. 1).

As Figure 1 demonstrates, most causes belong to Litany, which is the first and most tangible layer with 9 causes: 


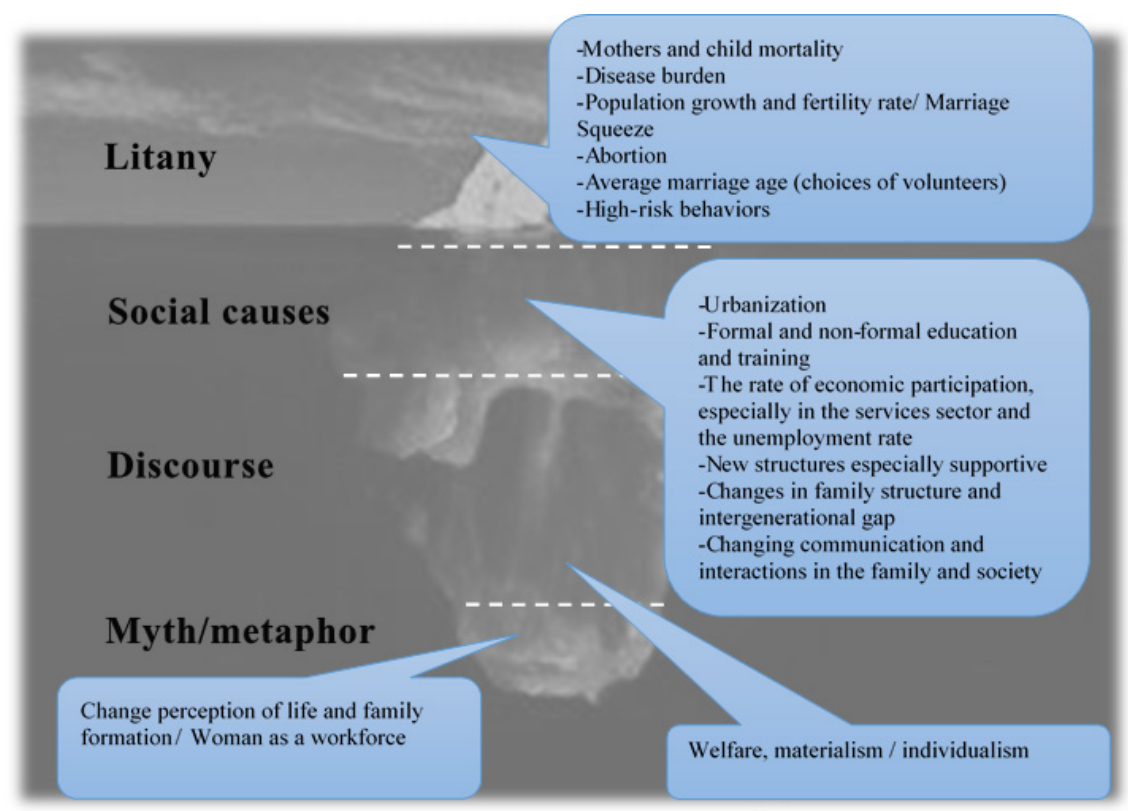

Fig. 1. Layer analysis of causes of decreasing population in Iran

child mortality $(32,36)$, maternal mortality $(21,35)$, disease burden (20), fertility rate $(9,37)$, marriage constraints $(9,23)$, abortion $(25,36)$, marriage age $(18,24)$, high-risk behaviors $(18,36)$, and badly-supervised and neglected children (38). The second layer (social causes) includes 5 causes: urbanization and education rate (9), economic participation rate and unemployment rate (34), new structures (especially supportive structures) $(33,36)$, changing family structures, and intergenerational gap (33). The discourse layer consists of 3 causes: welfare, materialism, and individualism $(17,19,22,26-31,33)$. The metaphor layer includes 2 causes: changing the perception of life and family formation, and women as workforce $(17,19$, 22, 26-31, 33).

\section{Discussion}

In the following section, the reasons for population decrease have been analyzed in 4 layers.

\section{Litany layer}

In this layer, the clear causes of population decrease led to the identification of 9 causes.

The mortality index of pregnant mothers and children is considered as one of the most important demographic indexes and is considered as a symbol of development (39). The death rate of mothers in Iran over the past 40 years has had a dramatic reduction, showing the effectiveness of implementing health system programs and other development sectors in Iran. However, this reduction is not enough to reach the Millennium Development Goal in 2015 (40). High mortality rate in children has adverse economic and social consequences (41). The mortality of mothers and children reduces the current population and the possibility of increasing the population in the future.

The second cause of population decrease was the burden of diseases. Non transmissible diseases are responsible for the deaths of over 35 million people each year, nearly two-thirds of the total deaths in the world (42). Studies related to the burden of diseases show that cardiovascular diseases, mental disorders, cancers, skeletal and muscular disorders, and AIDS are among the main causes of death in Iran which cause population decrease (43).

Demographic statistics show that in recent years, the rate of childbearing in Iranian families has been lower than the "fertility replacement rate" (44). Some scholars believe that increasing the fertility rate in Iran in the future is unlikely; moreover, by listing causes such as the increase in the level of urbanization and increase in the age of marriage, they have predicted a further decrease in the fertility rate (45). The increase in marriage squeeze in Iran is yet another cause affecting population decrease. In a simple definition, marriage squeeze can be defined as the imbalance in the number of men or women in marriage age. The results of marriage squeeze measurement in Iran have shown that it occurred for girls in 2006 and for boys in 2011 and 2016, and its severity would be more than girls' marriage squeeze in 2006 (46). Another barrier to population growth at this level is abortion. High statistics of abortion in Iran is unimaginable, as population growth is moving towards zero (47). The increase in the age of marriage and pregnancy, unplanned pregnancies, and the lack of desire for childbearing can be noted among causes of abortion (48).

The age of marriage is important in controlling population, as the increase in the age of marriage reduces fertility. The average age of marriage has increased over the recent years, which can be attributed to the change in people's attitudes toward economic issues, such as the increase in living costs, housing, unemployment, and marriage (46).

The high-risk behaviors known among Iranian youths include violence, suicide, careless driving, tobacco use, alcohol and drugs, high-risk sexual behaviors, unhealthy nutrition, and lack of exercise and physical activities. 
Risky behavior is considered as the most major risk for society health and the cause of many deaths $(49,50)$. Therefore, paying attention to this issue conduces to increase in the population.

According to statistics provided by the State Welfare Organization of Iran, there are 23000 orphans and badly supervised children in Iran (51) who experience parental separation and divorce and have irresponsible parents. The increase in badly supervised children without any support disturbs the future of the society in terms of creating a healthy family and childbearing (52).

\section{Social causes layer}

In this layer, 5 causes of population decrease have been discussed.

When there is a prospect of having a metropolis in the community and wealth is only available in city expansion, immigration and urbanization will increase. Population density, increase in living costs, reduction in the size of residential houses as barriers for more childbearing, and having a larger family are the consequences of this perspective (53).

New perspectives are related to large families as barriers to progress. Studies show that higher level of education increases the age of marriage and reduces fertility (54). Women's participation in economy has had consequences such as increased social welfare, and production level, and rising per capita income; however, along with the positive consequences, it has reduced the fertility rate (55).

Further affecting population growth are new structures such as single lives, and cohabitation, which is called white marriage in Iran, and has become widespread in big cities (46).

Another undeniable fact in urban life is the transformation in the family, which has taken place in various dimensions in Iran, including selecting the spouse, marriage, relationship between family members, changing attitudes, changing members' function and relationships between men and women, and changing lifestyles. Changes in the value system is also another transformation. These changes include infidelity and easy approach to divorce and disturbance in family members relationship (56).

\section{Discourse layer}

If we look more closely at the causes of population decrease and look for more fundamental reasons, we can find worldviews and discourses. The causes that have emerged in this layer have been rooted in the beliefs and values of individuals. When welfare, comfort, pleasure, materialism, and individualism that are the outcomes of Western culture and lifestyle become common among the values of a society, then, success, progress, and welfare are seen as having fewer children; such lifestyle is finally considered as the right way of life and standard of desirable life. Other studies have shown modernity to be effective in population decrease due to its welfare and pleasurecentered nature (57). Many scholars have identified individualism as an important factor that changes the attitudes towards matrimony $(58,59)$. The results of Aghajanian and Thompson's (2013) study showed an increase in the tendency towards individualism in Iran (60). Rastegar Khaled and Mohammadi (2014) have identified 4 causes for a decreasing population in Iran. Their results showed that secularism, individualism, and less attention to family values have a positive and consistent relationship with low fertility rates (61).

\section{Myth/metaphor layer}

When we analyze the underlying layer of the iceberg (CLA is the iceberg and litany and social causes are the tip, and a huge part of the iceberg (Discourse and Myth Layers) is hidden and not seen), the concept of "changing the perception of a family" emerges. Cultural changes that have taken place over time among people have changed the concept of family and childbearing. According to Abbasi-Shavazi and Askari-Nodoushan (2012), Iranian families are transitioning from traditional families to modern ones, and the signs of the crisis in this transition are obvious. Because of this transition, the family value system has changed (62). Marriage or family formation is in a transition situation from an unknown and destroyed tradition to a vague and poorly understood modernity. Cultural change has occurred not only in the role of the spouse and mother, but also in the philosophy of marriage and individuals' understanding of marriage. As women's beliefs have changed their role from women as spouses and mothers to women as economic powers, a shift has been created in attitudes toward marriage and spousal and maternal roles. The change in the role of women, increase in divorce statistics, marriage decrease, view change on the role of wife, and infidelity in marital relationships are among the damages of cultural change (63).

One reason for such damages is that the change from tradition to modernity has occurred before the new and industrial values are internalized in the society. Modern families without value internalization have endangered the stability of societies and the institution of the family. The new generation in Iran prefers to enjoy new social pleasures than to have responsibilities and family commitment (64-66).

\section{Conclusion}

The results of this study showed that various cultural, social, political, and economic causes affect population growth. However, it seems that the decrease in population growth in Iranian society is less the result of social planning and population control policies (although its role should not be ignored), and more the result of the value and structural changes that have occurred due to modernization in the society. It does not mean that the causes in the first layers have lower effects or importance. It is recommended that policymakers primarily address the discourse and metaphor layers to solve the problems. Welfare, materialism, and individualism, and the paradigm shift that have occurred in the concept and role of woman in the metaphor and discourse layers have changed the perception of life and family formation to single life or having fewer children. Therefore, phenomena such as urbanization and the increase in the age of marriage ap- 
pear in the social causes and litany layers. The problems identified in the social causes and litany layers will be solved by changing the discourse and metaphor layers. For example, changing the lifestyle and family identity and increasing the fertility rate can be achieved through the struggle with the metaphor that childbearing prevents progress. Based on CLA, it is necessary to pay attention to all known causes at different layers in population planning for Iran.

\section{Strengths and limitations}

CLA method was employed to identify the underlying reasons in the discourse and metaphor for the problem of population decline and the failure of policies in this area in Iran. The limitation of this study was that only documentary analysis was done, while interviews with policymakers and decision-makers in this area can enhance the findings of the study.

\section{Conflict of Interests}

The authors declare that they have no competing interests.

\section{References}

1. MohammadiLaini MB, Gholami S. Population decrease and its effect on the health of individual and Family from the perspective of Islam. J Relig Health. 2015;2(2):62-73.

2. McCann P. Urban futures, population ageing and demographic decline. Cambridge J Reg Econ Soc. 2017;10(3):543-57.

3. Robey B, Rutstein SO, Morris L. The fertility decline in developing countries. Sci Am. 1993;269(6):60-7.

4. Abbasi Shavazi M. Recent changes and the future of fertility in the Islamic Republic of Iran. In: Population Bulletin of the United Nations: Completing the Fertility Transition. United Nations Publishers; 2009.

5. Jones GW. recent fertility trends, policy responses and fertility prospects in low fertility countries of East and southeast asia [Internet]. United Nations, Department of Economic and Social Affairs, Population Division; 2011. Available from: http://www.un.org/esa/population/publications/expertpapers/20115 Jones Expert- Paper FINAL ALL-Pages.pdf

6. Aghajanian A, Mehryar AH. Fertility transition in the Islamic Republic of Iran: 1976-1996. Asia-Pacific Popul J. 1999;14(1):21-42.

7. Abbasi-Shavazi MJ, McDonald P. Family change in Iran: Religion, revolution, and the state. In: International Family Change. Routledge; 2012. p. 191-212.

8. Abbasi MJ, Mehryar A, Jones G, McDonald P. Revolution, war and modernization: Population policy and fertility change in Iran. J Popul Res. 2002;19(1):25-46.

9. statistical center of Iran. Population and Housing Census. 2011.

10. Haghdoost A, Pourhosseini SS, Emami M, Dehnavieh R, Barfeh T, Mehrolhassani MH. Foresight in health sciences using CLA method. Med J Islam Repub Iran. 2017;31(1):492-9.

11. Inayatullah S. Causal Layered Analysis. Futur J. 1998;30(8):815-29.

12. Inayatullah S, Song M-M. Visions and scenarios of democratic governance in Asia 2030. Futures. 2014;60:1-13.

13. Barber M. Solving the futures challenge-all you need is a CLA. Futures. 2010;42(2):170-3.

14. Son H. Alternative future scenarios for South Korea in 2030. Futures. 2013;52:27-41.

15. Inayatullah S. Causal layered analysis defined. Futurist. 2014;48(1):26.

16. Sapsford R, Jupp V. Data collection and analysis. 2th ed. London: Sage; 2006. 139-144.

17. Health Services Management Research Center. Iranian Demographic Policy (Considerations and Perspectives). Kerman; 2014.

18. Population Health Family and Schools Office. Youth health document. Tehran; 2014

19. AyatollahKhamenei. Demographic polices. Tehran; 2014.

20. statistical center of Iran, Ministry Of Health and Medical Education. Iran Demographic and Health Survey - 2010. 2010.

21. Khosravi A, Najafi F, Rahbar MR, Motlagh ME, Kabir MJ. Health Indicators in the Islamic Republic Iran. Khosravi A, Rahbar MR, editors. Tehran: Ministry of Health and Medical Education; 2009. 21$89 \mathrm{p}$.

22. Haghdoost AA, Khayatzadeh-Mahani A, Mehrolhassani M, Zolala F. analysis of the general population policies of the supreme leader Ayatollah Khamenehei. Kerman; 2014.

23. Statistical center of Iran. Time series of the population. 2017.

24. Statistical center of Iran. Time series for marriage and divorce. 2016.

25. Iranian Legal Medicine Organization. Abortion Report. 2015.

26. Presidential organization. The first program of economic, social and cultural development of the Islamic Republic of Iran. 1989.

27. Presidential organization. The second program of economic, social and cultural development of the Islamic Republic of Iran. 1995.

28. Presidential organization. The third program of economic, social and cultural development of the Islamic Republic of Iran.

29. Presidential organization. The fourth program of economic, social and cultural development of the Islamic Republic of Iran. 2005.

30. Presidential organization. The fifth program of economic, social and cultural development of the Islamic Republic of Iran. 2011.

31. Presidential organization. The sixth program of economic, social and cultural development of the Islamic Republic of Iran. 2017.

32. Statistical Center of Iran. Child mortality in Iran Indices and trends 1956 to 2021.2014

33. Islamic - Iranian Model of Progress Center. Islamic - Iranian Model of Progress. 2011.

34. Statistical Center of Iran. Indices of employment and unemployment 1997-2012. 2012.

35. Statistical Center of Iran. Health Indicators 2001-2014. 2014.

36. Health Services Management Research Center,Institute For Future Studies In Health KU of MS. Adolescent and Youth Reproductive Health Document Islamic Republic of Iran. 2015.

37. Statistical center of Iran. Population and Housing Census. 2006.

38. office of children and adolescent. street children report. 2016.

39. Bhutta ZA, Das JK, Bahl R, Lawn JE, Salam RA, Paul VK, et al Can available interventions end preventable deaths in mothers, newborn babies, and stillbirths, and at what cost? Lancet. 2014;384(9940):347-70.

40. Mohammadi Y, Parsaeian M, Mehdipour P, Khosravi A, Larijani B, Sheidaei A, et al. Measuring Iran's success in achieving Millennium Development Goal 4: a systematic analysis of under-5 mortality at national and subnational levels from 1990 to 2015. Lancet Glob Heal. 2017;5(5):e537-44.

41. Liu L, Oza S, Hogan D, Perin J, Rudan I, Lawn JE, et al. Global, regional, and national causes of child mortality in 2000-13, with projections to inform post-2015 priorities: an updated systematic analysis. Lancet. 2015;385(9966):430-40.

42. Peykari N, Hashemi H, Dinarvand R, Haji-Aghajani M, Malekzadeh $\mathrm{R}$, Sadrolsadat A, et al. National action plan for non-communicable diseases prevention and control in Iran; a response to emerging epidemic. J Diabetes Metab Disord. 2017;16(1):3.

43. Forouzanfar MH, Sepanlou SG, Shahraz S, BESc PN, Pourmalek F, Lozano R, et al. Evaluating causes of death and morbidity in Iran, global burden of diseases, injuries, and risk factors study 2010. Arch Iran Med. 2014;17(5):304.

44. McDonald P, Hosseini-Chavoshi M, Abbasi-Shavazi MJ, Rashidian A. An assessment of recent Iranian fertility trends using parity progression ratios. Demogr Res. 2015;32:1581-602.

45. Hosseini-Chavoshi M, Abbasi-Shavazi MJ, McDonald P. Fertility, Marriage, and Family Planning in Iran: Implications for Future Policy. Popul Horizons. 2016;13(1):31-40.

46. Aghajanian A, Vaezzade S, Kohan JA, Thompson V. Recent Trends of Marriage in Iran. Open Fam Stud J. 2018;10(1).

47. Mahdi Shirzad MA. Fertility behaviour of Iranian women: a community-based, cross-sectional study. Arch Iran Med. 2015;18(1):2.

48. Erfani A. Levels, trends and correlates of abortion in Tehran, Iran: 2009-2014. Int Perspect Sex Reprod Health. 2016;42(2):93-101.

49. Abbasi-Ghahramanloo A, Fotouhi A, Zeraati H, Rahimi-Movaghar A. Prescription drugs, alcohol, and illicit substance use and their 
correlations among medical sciences students in Iran. Int $\mathrm{J}$ high risk Behav Addict. 2015;4(1)

50. Mirzazadeh A, Nedjat S, Navadeh S, Haghdoost A, Mansournia MA, McFarland W, et al. HIV and related risk behaviors among female sex workers in Iran: bias-adjusted estimates from the 2010 National Bio-Behavoral Survey. AIDS Behav. 2014;18(1):19-24.

51. Office of Children's Affairs. Children's Affairs report. 2012.

52. Vameghi M, Sajadi H, Rafiey H, Rashidian A. The socioeconomic status of street children in Iran: a systematic review on studies over a recent decade. Child Soc. 2014;28(5):352-65.

53. Holton S, Fisher J, Rowe H. Attitudes toward women and motherhood: their role in Australian women's childbearing behaviour. Sex Roles. 2009;61(9-10):677.

54. Hazan M, Zoabi H. Do highly educated women choose smaller families? Econ J. 2014;125(587):1191-226.

55. Reshadat S, Zangeneh A, Saeidi S, Ghasemi SR, Rajabi Gilan N, Abbasi S. Investigating the economic, social and cultural factors influencing total fertility rate in Kermanshah. J Maz Univ Med Sci. 2015;25(127):108-12.

56. Behjati-Ardakani Z, Navabakhsh M, Hosseini SH. Sociological study on the transformation of fertility and childbearing concept in Iran. J Reprod Infertil. 2017;18(1):153.

57. Jokar M. Modernity, lifestyle changes and population decline in Iran. Women Fam [Internet]. 2014;2(2):39-69. Available from: https://www.sid.ir/en/journal/ViewPaper.aspx?ID=478859

58. Randles J, Avishai O. Saving Marriage Culture "One Marriage at a Time": Relationship Education and the Reinstitutionalization of Marriage in an Era of Individualism. Qual Sociol. 2018;41(1):21-40.

59. Kislev E. Happiness, Post-materialist Values, and the Unmarried. J Happiness Stud. 2018;19(8):2243-65.

60. Aghajanian A, Thompson V. Recent divorce trend in Iran. J Divorce Remarriage. 2013;54(2):112-25.

61. Rastegar Khaled A, Mohammadi M. Cultural changes and fertility decline in Iran. Appl Sociol. 2016;26(58):159-80.

62. Abbasi-Shavazi MJ, Askari-Nodoushan A. Family life and developmental idealism in Yazd, Iran. Demogr Res. 2012;26:207.

63. Zahedi M, Nazoktabar H. Modernization and crisis changes in family (A survey on new problems in family in urban area of Mazandaran Province). Soc Stud Res Iran. 2014;3(3):357-82.

64. Mehran G. The paradox of tradition and modernity in female education in the Islamic Republic of Iran. Educ Educ Res. 2003;47(3):269-86.

65. Abu-Lughod L. Remaking women: Feminism and modernity in the Middle East. Princeton University Press; 1998. 25-50 p.

66. Sadeghi F. Negotiating with modernity: Young women and sexuality in Iran. Comp Stud South Asia, Africa Middle East. 2008;28(2):250-9. 